Subscriber access provided by Red de Bibliotecas del CSIC

Environmental Processes

\title{
Solid and aqueous speciation of yttrium in passive remediation systems of acid mine drainage
}

\author{
Alba Lozano, Alejandro Fernandez-Martinez, Carlos Ayora, Devis \\ Di Tommaso, Agnieszka Poulain, Mauro Rovezzi, and Carlo Marini
}

Environ. Sci. Technol., Just Accepted Manuscript • DOI: 10.1021/acs.est.9b01795 • Publication Date (Web): 22 Aug 2019

Downloaded from pubs.acs.org on August 26, 2019

\section{Just Accepted}

"Just Accepted" manuscripts have been peer-reviewed and accepted for publication. They are posted online prior to technical editing, formatting for publication and author proofing. The American Chemical Society provides "Just Accepted" as a service to the research community to expedite the dissemination of scientific material as soon as possible after acceptance. "Just Accepted" manuscripts appear in full in PDF format accompanied by an HTML abstract. "Just Accepted" manuscripts have been fully peer reviewed, but should not be considered the official version of record. They are citable by the Digital Object Identifier (DOI®). "Just Accepted" is an optional service offered to authors. Therefore, the "Just Accepted" Web site may not include all articles that will be published in the journal. After a manuscript is technically edited and formatted, it will be removed from the "Just Accepted" Web site and published as an ASAP article. Note that technical editing may introduce minor changes to the manuscript text and/or graphics which could affect content, and all legal disclaimers and ethical guidelines that apply to the journal pertain. ACS cannot be held responsible for errors or consequences arising from the use of information contained in these "Just Accepted" manuscripts. 
4 Alba Lozano ${ }^{a, b^{*}}$, Alejandro Fernández-Martínez $z^{c}$, Carlos Ayora $^{a, b}$, Devis Di Tommaso ${ }^{d}$,

\section{passive remediation systems of acid mine}

\section{drainage}

\author{
Agnieszka Poulain ${ }^{e}$, Mauro Rovezzif, Carlo Marini ${ }^{g}$ \\ ${ }^{\text {a }}$ Institute of Environmental Assessment and Water Research, (IDAEA-CSIC), Jordi \\ Girona 18-26, 08034 Barcelona, Spain \\ ${ }^{\text {b }}$ Grup de Mineralogia Aplicada i Geoquímica de Fluids, Departament de Cristal- \\ lografia, Mineralogia i Dipòsits Minerals, Facultat de Geologia, Universitat de \\ Barcelona (UB), C/Martí Franquès, S/N, Barcelona, Spain
${ }^{\mathrm{c}}$ Univ. Grenoble Alpes, Univ. Savoie Mont Blanc, CNRS, IRD, IFSTTAR, ISTerre, 38000 Grenoble, France

${ }^{\mathrm{d}}$ School of Biological Sciences, Queen Mary University of London, Mile End Road, London, E1 4NS, UK

${ }^{\mathrm{e}}$ ESRF, The European Synchrotron, 71 Avenue des Martyrs, Grenoble 38000, France ${ }^{\mathrm{f}}$ Univ Grenoble Alpes, CNRS, IRD, Irstea, Météo France, OSUG, FAME, 38000 Grenoble, France

${ }^{\mathrm{g}}$ CELLS-ALBA Synchrotron Radiation Facility, Carrer de la Llum 2-26,08290 Cerdanyola del Valles, Barcelona, Spain Corresponding author: Alba Lozano (allba.lozano@idaea.csic.es)

\section{Solid and aqueous speciation of yttrium in}




\section{ABSTRACT}

22 Yttrium belongs to the rare earth elements (REE) together with lanthanides and scandium. REE are commonly used in modern technologies, and their limited supply has made it necessary to look for new alternative resources. Acid mine drainage (AMD) is a potential resource since is moderately enriched in REE. In fact, in passive remediation systems, which are implemented to minimize the environmental impacts of AMD, REE are mainly retained in basaluminite, an aluminum hydroxysulfate precipitate. In this study, the solid and liquid speciation and the local structure of yttrium were studied in high sulfate aqueous solutions, basaluminite standards and samples from remediation columns using synchrotron-based techniques and molecular modeling. Pair distribution function (PDF) analyses and ab initio molecular dynamics density functional theory models of the yttrium sulfate solution show that the $\mathrm{YSO}_{4}{ }^{+}$ion pair forms a monodentate inner sphere complex. Extended X-ray absorption fine structure (EXAFS) and PDF analyses show that $\mathrm{Y}$ is retained by basaluminite forming a monodentate inner-sphere surface complex at the aluminum hydroxide surface. EXAFS of the column samples show that its signal is represented in more than $75 \%$ by the signal of a basaluminite which $\mathrm{YSO}_{4}{ }^{+}$is forming an inner-sphere complex. The atomic vision of the REE configuration in AMD environments could help for a deeper research of the REE recovery from waste generated in the AMD remediation systems. 
Yttrium belongs to Rare Earth Elements (REE) group, also composed by lanthanides and scandium. REE are necessary for the development of modern technologies, and specifically, yttrium as important applications, for instance, in fluorescent lamps as phosphors, ${ }^{1}$ and in aircraft industry, used in the thermal barrier coatings for jet engines. ${ }^{2}$ The REE increasing demand but low worldwide supply has led to consider REE as critical raw materials boosting searches for alternative resources, such as recycling used stocks or identifying new geological sources of these elements. Because the REE concentrations in acid mine drainage (AMD) are from one to two orders of magnitude higher than the average concentrations in natural waters, ${ }^{3}$ it may be possible to perform secondary REE recovery from precipitates from AMD neutralization in passive remediation systems. The active systems were developed to minimize the environmental impacts of AMD and they are used worldwide. ${ }^{4,5}$ However, due to the high water 54 content, sludge storage has substantial operational costs and environmental concerns. ${ }^{6,7}$ In contrast, passive remediation systems, which have been developed extensively in recent decades, ${ }^{8-11}$ allow the AMD neutralization generating lower amounts of solid waste precipitates. Ayora et al. documented nearly complete aqueous REE retention in two laboratory columns simulating a disperse alkaline substrate (DAS), a passive treatment already implemented in the field, for two highly acidic AMD (SW Spain). ${ }^{12,13}$ The REE were scavenged by basaluminite, a mineral precipitated in the columns, which also presented $\mathrm{Y}$ enrichment due to the higher yttrium concentration with respect to the rest of REE in the two treated AMD. Basaluminite, an aluminum oxy-hydroxysulfate $\left(\mathrm{Al}_{4}\left(\mathrm{SO}_{4}\right)(\mathrm{OH})_{10} \cdot 5 \mathrm{H}_{2} \mathrm{O}\right)$, precipitates in acidic environments as a consequence of the natural attenuation of the AMD when mixing with more alkaline waters, or due to the induced neutralization of the acid waters, when the solution $\mathrm{pH}$ reaches $\sim 4{ }^{14}$ 
Basaluminite is considered a nanomineral, with a short-range order, around $1 \mathrm{~nm}$ of coherent domain size, which is described as layers of Al-octahedra with structural point defects and with the presence of sulfate groups as outer-sphere complexes between the Al layers. ${ }^{15}$

Similarly to the REE uptake by basaluminite in DAS treatments, Gammons et al., reported the precipitation of hydrous aluminum oxides accompanied with a decrease in REE concentration from AMD when mixed with natural water. ${ }^{16}$ Recently, the scavenge of REE by basaluminite precipitates has been described as a sorption mechanism. ${ }^{17}$ AMD is characterized to contain high loads of dissolved sulfate and the affinity of REE to form aqueous species with sulfate is very high, the $\mathrm{MSO}_{4}{ }^{+}$aqueous complex being the more abundant in AMD solutions. ${ }^{18}$ Sorption of dissolved REE from sulfate-rich waters onto basaluminite is thus described as the sorption of the $\mathrm{MSO}_{4}{ }^{+}$aqueous complex via ligand exchange with a surface site of basaluminite, forming a monodentate surface complex with the Al-octahedron as one proton is released. ${ }^{17}$ Here, a structural description of the aqueous $\mathrm{YSO}_{4}{ }^{+}$complex and of the local environment of the surface complex formed upon adsorption onto basaluminite are reported.

Most of the previous studies reporting the adsorption mechanisms of REE using X-ray absorption spectroscopy and Extended X-ray Absorption Fine Structure (EXAFS) described the adsorption of free REE ions onto the surface of metal oxides. ${ }^{19-22}$ However, the AMD environments show a high concentration of dissolved sulfate, which presents high affinity for aqueous REE (M). Thus, the $\mathrm{MSO}_{4}{ }^{+}$aqueous complex is the major REE species in solution and explains that the sorption models of REE in AMD precipitates might be better explained in terms of $\mathrm{MSO}_{4}{ }^{+}$sorption. 
The structure of the first hydration shell of lanthanides and yttrium has been well characterized. ${ }^{23-28}$ The coordination number $(\mathrm{CN})$ of the first hydration shell changes from an average of $\mathrm{CN} \sim 9$ oxygen atoms for light REE (LREE La to Pm) to $\mathrm{CN} \sim 8$ oxygen atoms for heavy REE (HREE Tb to $\mathrm{Lu}$ ), with intermediate values for medium REE (MREE Pm to Gd). ${ }^{27}$ This behavior is explained by the continuous decrease in ionic radii with the atomic number. ${ }^{27,29,30}$ The ionic radius of yttrium is between that those of Ho and Dy, so it is typically considered an HREE with a first hydration shell of $\mathrm{CN} \sim 8$ oxygen atoms. There are several studies describing aqueous complexes of REE with different ligands. REE easily forms inner-sphere complexes with carbonate and phosphate in solution ${ }^{31-33}$ whereas chloride and nitrate forms inner-sphere complexes at concentrations higher than $10 \mathrm{M}^{23,25}$ In the case of sulfate, no information about the geometry of $\mathrm{MSO}_{4}{ }^{+}$complexes has been reported so far despite their strong binding affinity. ${ }^{18}$

The objective of this study is to elucidate the structure of Y adsorbed onto basaluminite. Due to its chemical similarities with HREE, this allow us to assume similar structural configuration for this sub-group. Moreover, this element was one of the most concentrated in waste samples allowing performing X-ray absorption spectroscopy experiments. Since the $\mathrm{YSO}_{4}{ }^{+}$aqueous complex is adsorbed onto the mineral, ${ }^{17}$ a previous characterization of the geometry of the aqueous complex has been carried out. Finally a quantification of Y-species in basaluminite solids precipitated from AMD treatments has been performed. Structural studies were performed using EXAFS and pair distribution function (PDF) analyses of aqueous and solid samples combined with ab initio molecular dynamics (AIMD) simulations of the aqueous $\mathrm{YSO}_{4}{ }^{+}$complexes.

Two hypotheses are used to investigate the local structure of the aqueous $\mathrm{YSO}_{4}{ }^{+}$ion pair: (1) an outer-sphere complex, with water located between $\mathrm{Y}^{3+}$ and $\mathrm{SO}_{4}{ }^{2-}$, and (2) an 
114 inner sphere complex. In the latter case, two more hypotheses must be considered: (a) a 115 monodentate complex, with one oxygen atom shared between the sulfate and the fist 116 coordination sphere of $\mathrm{Y}^{3+}$, and (b) a bidentate complex, with two oxygen atoms shared

117 between the yttrium hydration sphere and the sulfate group.

118 Once the structure of the aqueous solution is fully described, different hypotheses have 119 been considered to interpret the $\mathrm{YSO}_{4}{ }^{+}$surface complexation onto the Al120 oxyhydroxysulfate: the formation of (1) a monodentate inner sphere complex, (2) a bidentate mononuclear inner-sphere complex, (3) a bidentate binuclear inner sphere complex.

Finally, to determine semi quantitatively the yttrium species in solids from column samples, linear combination fits were performed using the most representative references.

\section{MATERIAL AND METHODS}

Different basaluminites doped with $\mathrm{Y}$ were prepared for HEXS and EXAFS experiments. To ensure maximum $\mathrm{Y}$ incorporation into the solid, sorption and coprecipitation experiments were performed at $\mathrm{pH} 6,{ }^{17}$ avoiding higher $\mathrm{pH}$ values where

$131 \mathrm{YCO}_{3}{ }^{+}$aqueous species could be present. ${ }^{34} \mathrm{~A}$ basaluminite sample with sorbed $\mathrm{YSO}_{4}{ }^{+}$ (B-YSO4-ads) was obtained from a suspension of $1 \mathrm{~g} / \mathrm{L}$ of solid in $0.11 \mathrm{Y}\left(\mathrm{NO}_{3}\right)_{3} \cdot 6 \mathrm{H}_{2} \mathrm{O}$ and $0.25 \mathrm{M} \mathrm{Na}_{2} \mathrm{SO}_{4}$ solution for 5 hours at a constant $\mathrm{pH}$ of 6 . At these conditions, the major species in solution was $\mathrm{YSO}_{4}{ }^{+}$, which is supposedly the aqueous $\mathrm{Y}$ specie sorbed on the solid surface. ${ }^{17} \mathrm{~A}$ basaluminite sample coprecipitated with Y (B-Ycop) was obtained using the basaluminite synthesis method adding $1 \mathrm{M} \mathrm{Y}\left(\mathrm{NO}_{3}\right)_{3} \cdot 6 \mathrm{H}_{2} \mathrm{O}$ in the 
137 acid solution of $0.05 \mathrm{M} \mathrm{Al}_{2}\left(\mathrm{SO}_{4}\right)_{3} \cdot 18 \mathrm{H}_{2} \mathrm{O}$ (see Chapter $\mathrm{S} 1$ of the SI). Basaluminite and 138 nanoboehmite samples with sorbed $\mathrm{Y}^{3+}$ (B-Yads and A-Yads, respectively) were also 139 prepared from a suspension of $1 \mathrm{~g} / \mathrm{L}$ of solid in $0.011-0.11 \mathrm{M} \mathrm{Y}\left(\mathrm{NO}_{3}\right)_{3} \cdot 6 \mathrm{H}_{2} \mathrm{O}$ solution 140 for 5 hours, and the $\mathrm{pH}$ was maintained at $\sim 6$ at room temperature, respectively (the 141 synthesis protocol is described in detail in Chapter S1 of the SI). At these conditions, 142 the major species of $\mathrm{Y}$ is $\mathrm{Y}^{3+}$. In all cases, the suspensions were centrifuged at $4500 \mathrm{rpm}$ 143 for 15 minutes, the supernatant was filtered through $0.2 \mu \mathrm{m}$ membranes and kept for 144 ICP analysis. The solids were rinsed several times with deionized water and oven dried for 48 hours at a maximum temperature of $40^{\circ} \mathrm{C}$.

High-energy X-ray scattering (HEXS) and EXAFS experiments of aqueous solutions with $\mathrm{Y}$ and $\mathrm{YSO}_{4}{ }^{+}$were carried out. For the HEXS measurements, an aqueous solution of free yttrium ions (Y-sol) was prepared with $0.1 \mathrm{M} \mathrm{Y}\left(\mathrm{NO}_{3}\right)_{3} \cdot 6 \mathrm{H}_{2} \mathrm{O}$ at $\mathrm{pH} 3.2$, and a solution containing $\mathrm{YSO}_{4}{ }^{+}$as the major aqueous complex $\left(\mathrm{YSO}_{4}\right.$-sol) were prepared by mixing equal amounts of $0.2 \mathrm{M} \mathrm{Y}\left(\mathrm{NO}_{3}\right)_{3} \cdot 6 \mathrm{H}_{2} \mathrm{O}$ and $0.2 \mathrm{M} \mathrm{Na}_{2} \mathrm{SO}_{4}$ at $\mathrm{pH}$ 3. For the EXAFS measurements, a solution with the free $\mathrm{Y}^{3+}$ ion $(\mathrm{Y}$-sol) with a composition of $0.01 \mathrm{M} \mathrm{YCl}_{3} \cdot 6 \mathrm{H}_{2} \mathrm{O}$ at $\mathrm{pH} 4.6$, and the solution of the $\mathrm{YSO}_{4}{ }^{+}$complex $\left(\mathrm{YSO}_{4}\right.$-sol) with a composition of $0.01 \mathrm{M} \mathrm{YCl}_{3} \cdot 6 \mathrm{H}_{2} \mathrm{O}$ and $0.01 \mathrm{M} \mathrm{Na}_{2} \mathrm{SO}_{4}$ at $\mathrm{pH} 2.9$, were prepared, 154 respectively. At these conditions, the major species in solution were $\mathrm{Y}^{3+}$ and $\mathrm{YSO}_{4}^{+}$ 155 (Fig. S1). The yttrium concentrations of the references are listed in Table S1, and a more comprehensive description of the syntheses is given in the Supporting Information 157 S1. 
159 Column samples were collected from two laboratory column experiments of Disperse 160 Alkaline Substrate (DAS), as described in Ayora et al. ${ }^{12}$ simulating the remediation systems of the two AMD from the Iberian Pyrite Belt region (SW Spain). The columns (9.6 cm inner diameter and $39 \mathrm{~cm}$ in height) consisted in a permeable mixture of grained limestone and wood shavings at a 1:1 weighed ratio. Samples W-MR-C1-4 and W-MRC1-5 belonged to columns which treated AMD from Monte Romero mine and W-AlmC3-8 and W-Alm-C3-9 samples belonged to columns which treated leaching of Almagrera mine tailing dam. Y concentration in different AMDs at the inlet ranged from 9 to $42 \mathrm{ppm}$, and sulfate concentrations 3.5 and $11.7 \mathrm{mg} / \mathrm{L}$. Physical-chemical parameters and water samples were collected every two weeks. Once the treatment finished after 18 weeks, the solid was divided in $2 \mathrm{~cm}$ thick slices and dried. The partitioning of $\mathrm{Al}, \mathrm{Fe}$ and REE was studied by performing a sequential extraction adapted from Torres and Auleda to the solid residues. ${ }^{35}$ The results showed in Ayora et al. concluded that REE were retained in basaluminite. ${ }^{10}$ The W-MR-C1-4, W-MR-C1-5, W-Alm-C3-8 and W-Alm-C3-9 samples were selected from the depth were maximum Al concentration was extracted from the solids, assuming the most enriched in basaluminite solid slice. These waste samples were used for EXAFS measurements and the Y concentrations for these samples are shown in Table S2.

Measurements of the $\mathrm{pH}$ values of the initial and final solutions were made with a Crison ${ }^{\circledR}$ glass electrode calibrated with buffer solutions of $\mathrm{pH} 2,4$ and 7 . The $\mathrm{Al}$ and $\mathrm{S}$ concentrations were measured by inductively coupled plasma optical emission spectroscopy (ICP-OES), and the Y concentration was measured by inductively coupled 
182 plasma mass spectrometry (ICP-MS). The aqueous speciation and saturation index of 183 the solid phases were calculated with the PHREEQC code ${ }^{36}$ using the Donnee 184 Thermoddem_V1.10 database ${ }^{37}$ provided by the Bureau de Recherches Géologiques et Minières (BRGM). Details of the analytical procedures and the database for the REE speciation are described in the Supporting Information S2.

The HEXS measurements were performed at the ID31 beamline at the European Synchrotron Radiation Facility (ESRF). The samples were loaded into 1.5 or $2 \mathrm{~mm}$ Kapton capillaries, and the HEXS patterns were obtained using a Pilatus $3 \mathrm{X}$ CdTe $2 \mathrm{M}$ detector. The data correction and generation of structure factors and pair distribution functions were performed with the PDFgetX3 software. ${ }^{38}$ PDF for aqueous solutions were obtained by subtracting the scattering signal of pure water from the total scattering signal of YSO4-sol sample and Y-sol sample, respectively. The differential pair distribution functions (d-PDF) for B-Ycop sample were obtained by subtracting the PDF signal of a pure synthetic basaluminite from the PDF of B-Ycop sample.

The EXAFS measurements of the samples B-Yads, B-Ycop, A-Yads, Y-sol and YSO4sol were performed at the Y K-edge $(17.038 \mathrm{keV})$ at the FAME beamline, ${ }^{39}$ BM30B at the ESRF. The EXAFS measurements of the B-YSO4 sample was performed at the Y K-edge (17.038 keV) at CLÆSS beamline (ALBA synchrotron). Atomistic models of $200 \mathrm{YSO}_{4}{ }^{+}$and $\mathrm{Y}^{3+}$ complexes adsorbed on a basaluminite surface with different initial configurations were employed in the data analysis to extract the $\mathrm{Y}$ local order parameters, including the neighbor distances, R, coordination number, N, and DebyeWaller factors, $\sigma^{2}$. The proportion of $\mathrm{Y}$ species present in each waste sample from column treatments was obtained by linear combination fitting (LCF) of the EXAFS spectra using the most representative reference compounds as the basis set. The 
experimental setup and the details of the data analysis are given in the Supporting Information S3.

208

209

210

211

212

213

214

215

The Ab Initio Molecular Dynamics (AIMD) simulations of an aqueous solution of yttrium(III) sulfate were carried out on a $\mathrm{Y}^{3+}-\mathrm{SO}_{4}{ }^{2-}-\mathrm{OH}^{-}$system embedded in a box of 61 water molecules. The simulations were conducted with the electronic structure code $\mathrm{CP} 2 \mathrm{~K} /$ Quickstep code, version $5.1{ }^{40} \mathrm{CP} 2 \mathrm{~K}$ implements density functional theory (DFT) based on a hybrid Gaussian plane wave. The revPBE generalized gradient approximations for the exchange and correlation terms were used together with the general dispersion correction termed DFT-D3. ${ }^{41,42}$ The simulations were carried out for 15 ps in the canonical (constant NVT) ensemble to maintain the average temperature at $\mathrm{T}=300 \mathrm{~K}$. An in-house Python code using DiffPy-CMI was developed to convert the AIMD trajectories to PDF signals. ${ }^{43}$ Details of the MD simulations are described in S4.

\section{RESULTS AND DISCUSSION}

\section{Geometry of the aqueous complex $\mathrm{YSO}_{4}{ }^{+}$}

The experimental (YSO4-sol, Y-sol) and theoretical (YSO4-calc) PDFs of the Ycontaining aqueous solutions, $0.1 \mathrm{M} \mathrm{YNO}_{3}$ and $\mathrm{YSO}_{4}$, are shown in Fig. 1. Background subtraction of the aqueous samples was performed using a deionized water background, which implies that the experimental PDFs shown here are differential PDFs (water subtracted). The background scale factor was adjusted to minimize the O-O correlation $(\sim 2.8 \AA)$ in the PDFs. All spectra show an intense peak at $2.37 \AA$, which corresponds to the Y-O interatomic distances to oxygen in the first coordination shell. The experimental PDF of the YSO4-sol sample shows a small and sharp peak at $1.45 \AA$ that corresponds unequivocally to the S-O interatomic distance in sulfate, and another 
smaller peak at $\sim 3.6 \AA$, which is absent in Y-sol sample. The DFT-based PDFs obtained 230 from AIMD simulations of the $\mathrm{YSO}_{4}{ }^{+}$aqueous complex also reproduced this latter peak. Analyses of the AIMD trajectories show that the $3.6 \AA$ distance between $\mathrm{Y}$ and $\mathrm{S}$ is consistent with the formation of a monodentate inner sphere complex (one shared oxygen) between the coordination shells of the sulfur and yttrium.
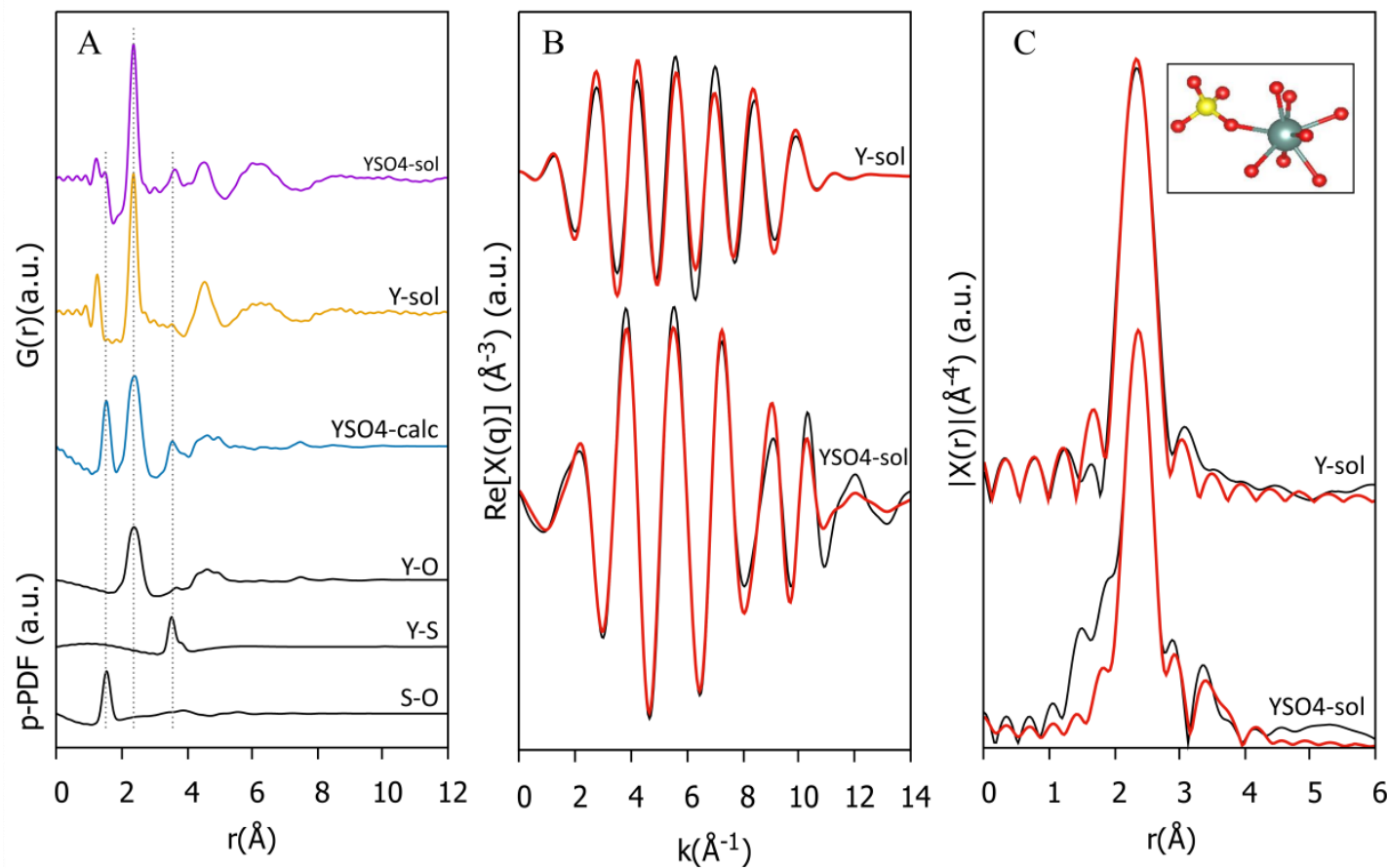

234

Figure 1. (A) Top: Experimental PDFs of YSO4-sol and Y-sol samples. Bottom: Simulated (AIMD) PDF (YSO4-calc) and partial PDFs of an $\mathrm{YSO}_{4}{ }^{+}$aqueous complex. (B) Fourier-filtered signal from 1.8 to $4.2 \AA$ for the EXAFS data. (C) EXAFS FT amplitude functions of the YSO4-sol sample. Black lines: experimental; red lines: fits. Simulated (AIMD) PDF and partial PDFs have been multiplied for visualization purposes: $\mathrm{YSO}_{4}$-cal $(\times 3), \mathrm{Y}-\mathrm{S}(\times 5)$ and $\mathrm{Y}-\mathrm{O}$ and $\mathrm{S}-\mathrm{O}(\times 2)$. Dashed lines indicate the position of the Y-O, Y-S and S-O bonds in YSO4-sol sample.

242 Fits of the EXAFS spectra of the aqueous solutions were performed using atomistic models from the AIMD simulations as initial structural models for the generation of the 
scattering paths. The results yielded an average Y-O distance of $2.37 \pm 0.02 \AA$ for the

245 Y-sol sample and $2.38 \pm 0.01 \AA$ for YSO4-sol (Table 1). The intense peak in the FT

246 function at $2.38 \AA$ for the two aqueous references represents the first solvation shell,

247 and its asymmetry reveals a distribution of Y-O interatomic distances, as reported

248 previously by Lindqvist et al. ${ }^{24}$ The coordination numbers $(\mathrm{CN})$ were $7.6 \pm 1.9$ and $7.9 \pm$

2490.9 for Y-sol and YSO4-sol, respectively, which are close to the expected value of 8 for

250 HREE. A second shell is visible in the FT of the YSO4-sol sample. It was fitted with a

251 Y-S distance of $3.50 \pm 0.04 \AA$, similar to that observed in the PDF of the same sample,

252 and a $\mathrm{CN}=1$. This corresponds to a monodentate coordination, matching the geometry

253 obtained from the AIMD simulations. The coordination number $\mathrm{CN}=1$ was kept fixed

254 in the EXAFS fitting to increase the stability of the fitting procedure, minimizing the number of parameters and excessive correlations between them. A multiple scattering path (Y-S-O) was included and was found to be relevant and to improve the fit. The

257 fitting parameters matched both the PDF and modeling results and indicated that the $258 \mathrm{YSO}_{4}{ }^{+}$aqueous species forms a monodentate inner-sphere complex.

Table 1. Modeling parameters of the $\mathrm{Y}$ K-edge EXAFS spectra of the $0.1 \mathrm{M} \mathrm{YSO}_{4}$ aqueous solution (the error is expressed in the parentheses after the last digit).

\begin{tabular}{|c|c|c|c|c|c|c|c|c|}
\hline Sample & Neighbor & path & $\mathrm{N}$ & $\sigma^{2}$ & $\Delta \mathrm{E}_{0}$ & $\mathrm{R}(\AA)$ & Var. & $\chi_{v}{ }^{2}$ \\
\hline Y sol & $1^{\text {st }}$ shell & $\mathrm{Y}-\mathrm{O}$ & $7(2)$ & $0.005(3)$ & $-2(3)$ & $2.37(2)$ & 4 & 354 \\
\hline \multirow[t]{3}{*}{ Y-SO4 sol } & $1^{\text {st }}$ shell & $\mathrm{Y}-\mathrm{O}_{1}$ & $7.9(9)$ & $0.007(2)$ & & $2.38(1)$ & 8 & 498 \\
\hline & $2^{\text {nd }}$ shell & Y-S & $1_{\text {fixed }}$ & $0.003(6)$ & $-1(1)$ & $3.50(4)$ & & \\
\hline & $3^{\text {rd }}$ shell & Y-S-O & $1_{\text {fixed }}$ & $0.015(19)$ & & $3.18(10)$ & & \\
\hline
\end{tabular}


261 The determined Y-O first shell coordination numbers and interatomic distances are 262 consistent with previous reports describing yttrium coordination shells with $\mathrm{N}=8$ and 263 Y-O distances of $2.36 \AA^{23,24,28}$ Likewise aqueous REE carbonate and phosphate 264 complexes, ${ }^{31-33}$ aqueous Y-SO4 ion-pairs form inner-sphere complexes. This result contrasts with other ligands such as chloride, which hardly forms inner sphere complexes at similar concentrations to those used in this study. ${ }^{23}$ Only the formation of monodentate complexation between Dy and $\mathrm{NO}_{3}$ with a distance of $3.57 \AA$ has been reported using MD simulations. ${ }^{26}$

\section{Local order of yttrium adsorbed into basaluminite}

HEXS measurements were performed on a pure basaluminite sample (B-pure) and on a sample of basaluminite coprecipitated with Y (B-Ycop). The PDFs are shown in Fig. 2 with the differential PDF obtained by subtracting the pure sample from the coprecipitated one. This approach has been previously used to examine the local order of different anions incorporated in poorly crystalline minerals, such as schwertmannite and basaluminite, and the desorption of sulfate from basaluminite when ageing at circumneutral $\mathrm{pH}$ values. ${ }^{15,46}$ The PDFs of the two samples are similar and show characteristic basaluminite peaks that correspond to the known interatomic distances (SO bond at $~ 1.46 \AA$, Al-O bonds at 1.88, 4, 4.8 and $6 \AA$ and Al-Al bonds at $3 \AA$ ). ${ }^{15,45}$ The differential PDF shows a main peak at $2.37 \AA$, which corresponds to the Y-O distance. This peak matches the distance from $\mathrm{Y}$ to the first solvation shell obtained from the EXAFS and PDF of the $\mathrm{Y}^{3+}$ and $\mathrm{YSO}_{4}{ }^{+}$aqueous solutions (Fig. 1). Another peak is present at $1.7 \AA$, which is tentatively assigned to a new Al-O distance of the Aloctahedra, due to probable distortions of the basaluminite. The existence of deformations in the structures of mineral nanoparticles upon oxyanion adsorption has 285 been previously observed. ${ }^{44,46}$ A smaller peak appears at $3.48 \AA$, which can be 
tentatively assigned to a $\mathrm{Y}-\mathrm{S}$ distance, though it is shorter than the $\mathrm{Y}-\mathrm{S}$ distance

287

288

289

290

291

292

293

294

295

296

297

reported for the $\mathrm{YSO}_{4}{ }^{+}$aqueous complex (Table 2 and Fig. 1A). This peak may also correspond to a Y-Al interatomic distance, which would be consistent with the formation of an inner-sphere complex, as suggested by Lozano et al. ${ }^{17}$ This hypothesis will be tested using different atomistic models for the fitting of the EXAFS data. Other peaks at longer distances are difficult to assign in the absence of a more detailed structural model.

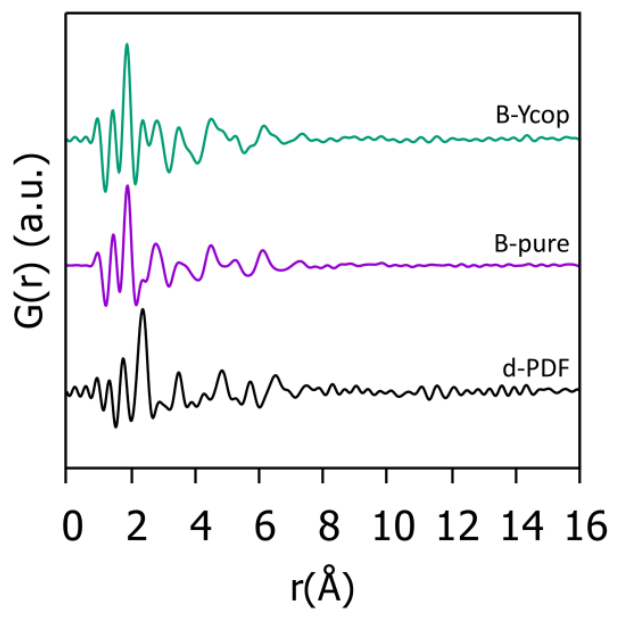

Figure 2. PDFs of basaluminite coprecipitated in the presence of $\mathrm{Y}$ (B-Ycop), pure basaluminite (B-pure) and differential PDF (d-PDF). The d-PDF spectrum has been amplified $(\times 3)$ for visualization purposes.

The $\mathrm{k}^{3}$-weighted EXAFS spectra for the solid references B-YSO4-ads, B-Y-ads, B-Ycop and A-Y-ads (Fig. 3) are indistinguishable and differ from the aqueous Y-sol and YSO4-sol spectra in that a slight oscillation becomes visible at 5-6 $\AA^{-1}$. In the B-YSO4ads the dominant $\mathrm{Y}$ species in solution is the $\mathrm{YSO}_{4}{ }^{+}$complex. However, in B-Y-ads, BYcop and A-Yads, the dominant Y species is $\mathrm{Y}^{3+}$. Still, these four samples show similar spectra. Since the common feature in these three samples is the presence of an $\mathrm{Al}$ adsorbent, and this feature agrees with that in the B-YSO4-ads EXAFS spectrum, we 
304 hypothesize that the higher frequency observed at 5-6 $\AA^{-1}$ (arrow in Fig. 3) may be 305 related to the presence of an $\mathrm{Al}$ backscatterer, rather than to a signal from an close 306 sulfate group. Both $\mathrm{Al}$ and $\mathrm{S}$ are light atoms with similar atomic numbers $(\mathrm{Z}=13$ and 16, respectively), which makes their backscattering functions difficult to distinguish via fitting of the EXAFS signal. These observations lead us to assume that the EXAFS measurements have poor sensitivity to the presence of $\mathrm{Y}-\mathrm{S}$ bonds in this system. However, a contribution from a sulfate shell for the two first samples cannot be ruled out.
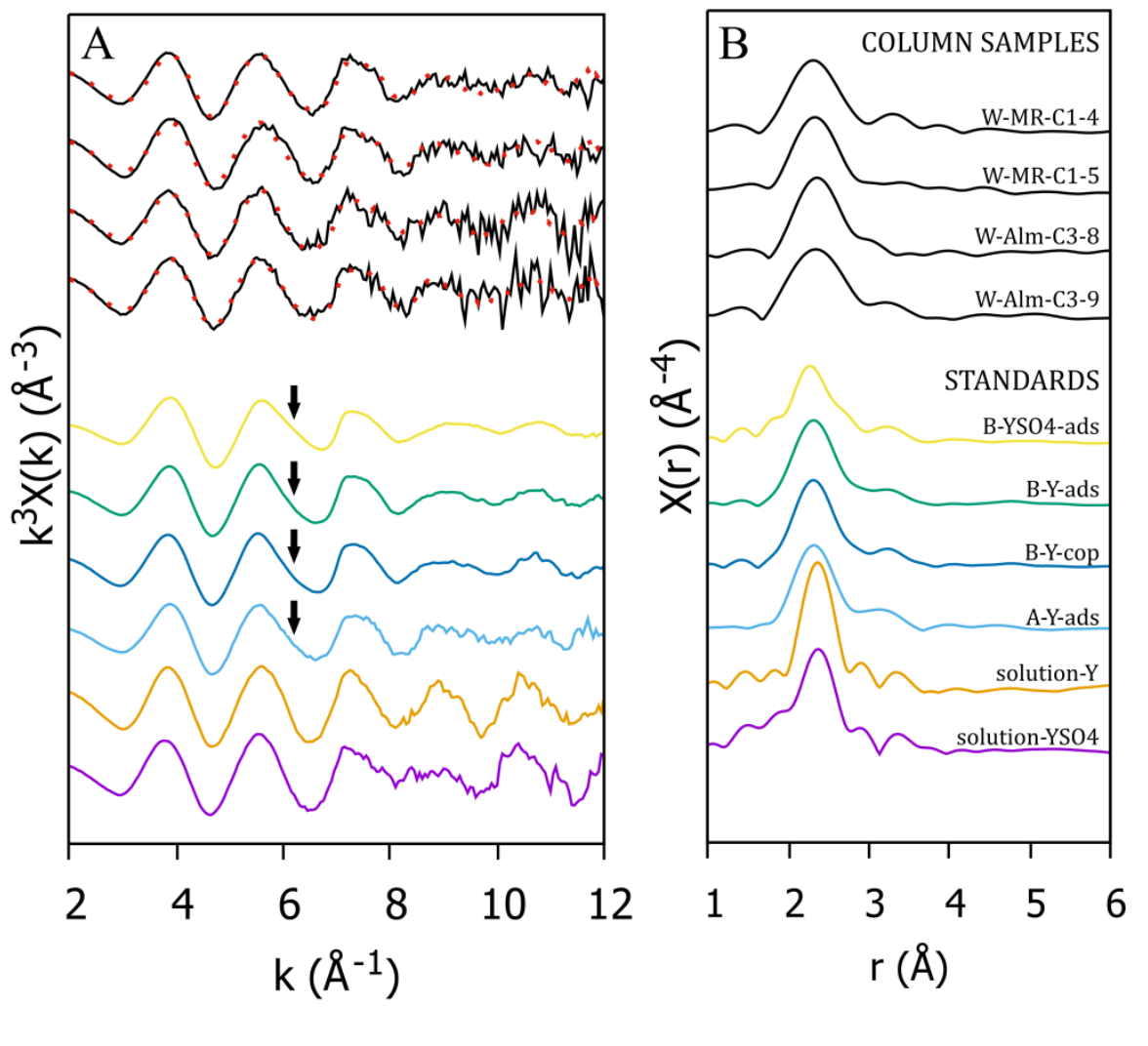

313 Figure $3 \cdot \mathrm{k}^{3}$-weighted EXAFS (A) and FT amplitude functions (B) for four waste 314 samples from column treatments W-MR-C1-3, W-MR-C1-4, W-Alm-C3-8, and W315 Alm-C3-9 (upper part) and solid standards (basaluminite sorbed with YSO4. (B-YSO4), basaluminite sorbed and coprecipitated with Y: B-Yads and B-Ycop, respectively) and 
317 aqueous solution (free ion and sulfate complex: Y-sol and YSO4-sol, respectively)

318 (bottom part). The dashed lines in the EXAFS signals of the column samples represent

319 LCF with B-Yads (basaluminite with sorbed yttrium) and YSO4-sol (solution of Y with

$320 \mathrm{SO}_{4}$ ) standards as the most representative references (results in Table 3). The arrows

321 indicate a frequency present in the solid standards.

322 Based on the previous information of the aqueous species and on the thermodynamic

323 model of REE sorption, ${ }^{17}$ the B-YSO4-ads EXAFS signal was fitted with three models

324 of different geometries of the $\mathrm{YSO}_{4}{ }^{+}$aqueous complex adsorbed onto basaluminite 325 surfaces via inner-sphere complexes (Fig. 4), to obtain an atomistic model representation: (A) a monodentate surface complex; (B) a bidentate mononuclear

327 surface complex and (C) a bidentate binuclear surface complex.
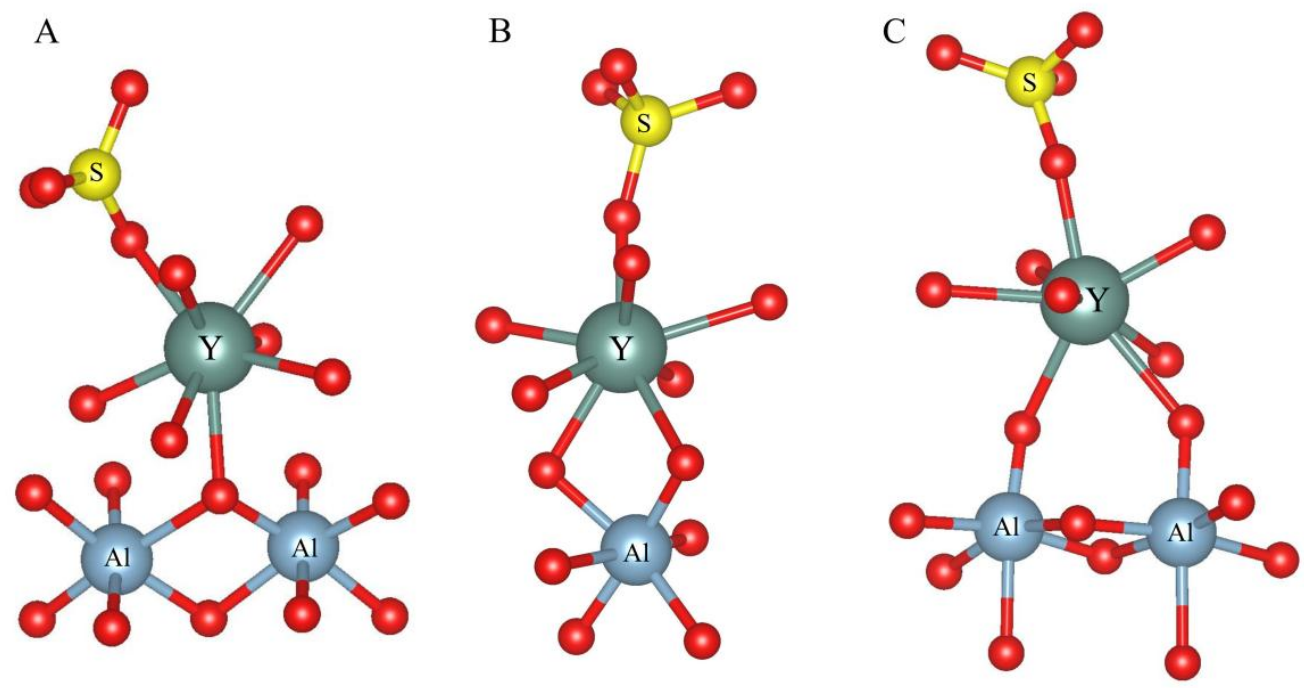

Figure 4. Atomistic representations of the three models of YSO4 aqueous complex adsorbed on the basaluminite-water interface. The different atomic positions of YSO4 to octahedral-Al are used to fit the EXAFS signal of the B-YSO4 sample. The three 
models show different inner-sphere surface complexes: (A) monodentate, (B) bidentate mononuclear and $(\mathrm{C})$ bidentate binuclear.

The EXAFS fits for B-YSO4-ads for the different models and the calculated parameters are given in Fig. 5 and Table 2, respectively. The first model represents a monodentate inner-sphere surface complex. The coordination number of the shells has been fixed based on information from another sources: The major aqueous species in solution was $\mathrm{YSO}_{4}{ }^{+}$, which, as supported by PDF and DFT data, forms a monodentate aqueous complex. Besides, the thermodynamic model of REE sorption on basaluminite indicated monodentate complexation of the $\mathrm{YSO}_{4}{ }^{+}$aqueous complex. ${ }^{17}$ With this information the fit was performed assuming $\mathrm{S}$ and $\mathrm{Al}$ coordination numbers equal to 1 and 2 , respectively, as it is shown in Fig. 4A. Besides, two oxygen paths were considered due to the Y-O length variation improving the fit. Thus, the fit yielded a first coordination shell with a Y-O distance range between 2.32 and $2.47 \pm 0.02 \AA$ with a fix coordination number of 8. The second shell was fitted yielding a Y-Al distance at $3.52 \AA$ with a fixed coordination number of $\mathrm{N}=2$, and a $\mathrm{Y}-\mathrm{S}$ distance at 3.33 with a fixed number of $\mathrm{N}=1$. This result is consistent with the monodentate inner-sphere complex of $\mathrm{Y}$ with one oxygen shared with two surface Al sites (Fig. 4A). The second model, the bidentate binuclear inner-sphere complex configuration, gave poorer results without structural significance and with higher $\chi_{v}{ }^{2}$ values (Table 2), so it was discarded. The third model was the bidentate binuclear, the first shell was fitted with a coordination number of $10 \pm$ 1.31 and a distance of $2.33 \AA$ A. The second shell was fitted with a S path yielding an Y-S distance of $3.34 \AA$ with a fix coordination number of $\mathrm{N}=1$, similar to that for the monodentate hypothesis, and with an $\mathrm{Al}$ path with a fixed coordination number of $\mathrm{N}=2$ giving a distance a bit longer, $3.92 \AA$. 
356 Overall, the monodentate inner-sphere surface complex gave the best fit results, which

357 was in accordance to the thermodynamic sorption model. Moreover, the bidentate

358 binuclear inner-sphere surface complexes yielded also a good fit with similar $\chi_{v}^{2}$ values

359 than the monodentate hypothesis, making this configuration also possible (Fig. 4C). In

360 both fits, the distances between Y-S are similar, 3.33, $3.34 \AA$, which is also observed in

361 the differential PDF of the B-Ycop reference. From the EXAFS data, the presence of a

362 bidentate binuclear surface complex cannot be ruled out. However, the thermodynamic

363 modeling and the EXAFS data both agree on the monodentate surface complex being

364 the one present at the basaluminite-water interface.
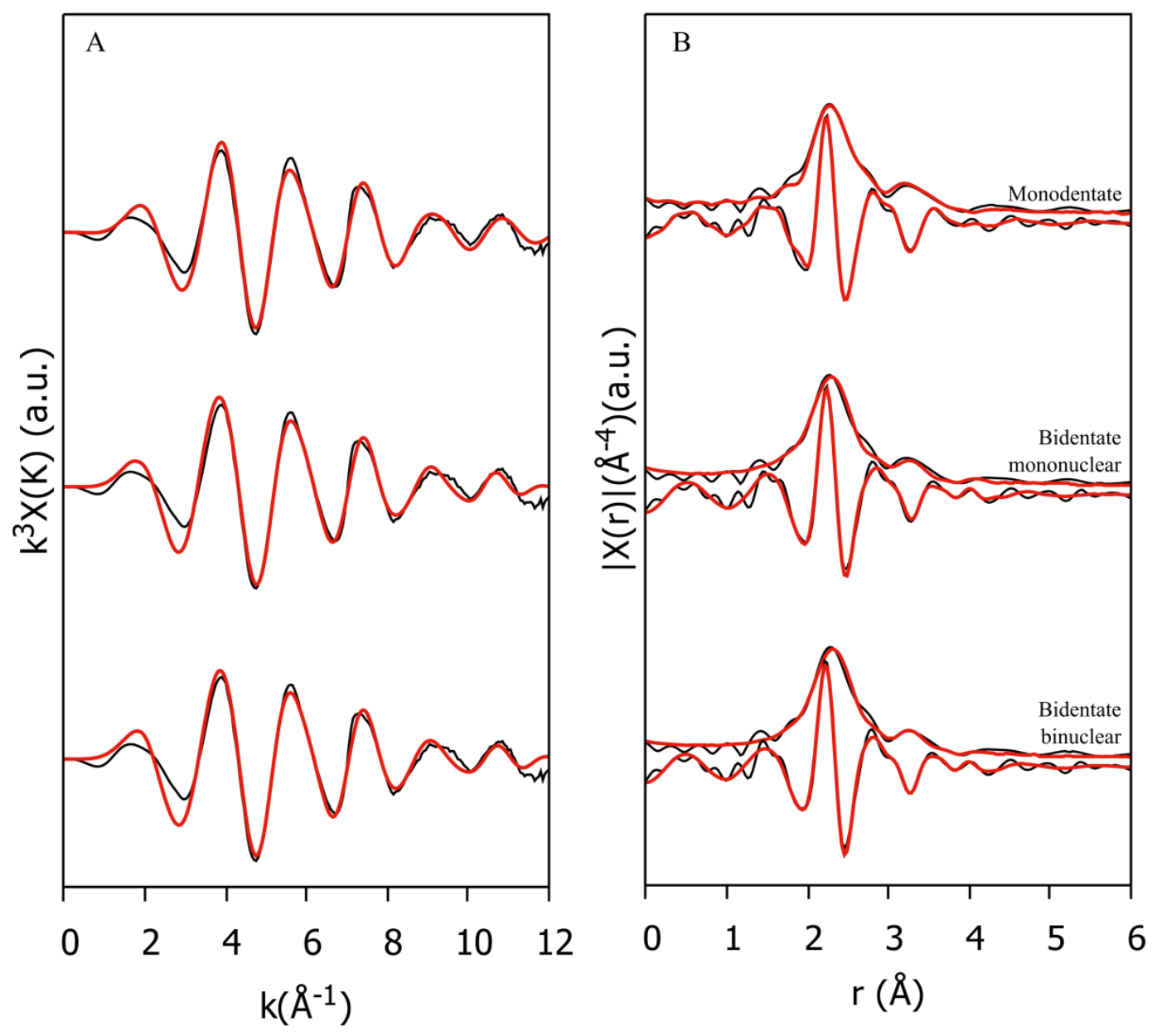
366 Figure 5. (A) The $\mathrm{k}^{3}$-weighted EXAFS spectra at the Y K-edge of the basaluminite with 367 YSO4 sorbed (B-YSO4 reference) and (B) its Fourier transform amplitude. The experimental and fitted curves are shown in black and red, respectively.

Table 2. Results of the EXAFS fits for B-YSO4 reference. Model 1: monodentate inner sphere. Model 2: bidentate mononuclear inner sphere. Model 3: bidentate binuclear inner sphere. Var. indicates independent variables. The best model is indicated with a star (*). The error is expressed in the parentheses after the last digit.

\begin{tabular}{|c|c|c|c|c|c|c|c|c|}
\hline Model & Neighbor & path & $\mathrm{N}$ & $\sigma^{2}$ & $\Delta \mathrm{E}_{0}$ & $\mathrm{R}$ & Var. & $\chi_{v}^{2}$ \\
\hline \multirow[t]{4}{*}{$1^{*}$} & $1^{\text {st }}$ shell & $\mathrm{Y}-\mathrm{O}_{1}$ & $6_{\text {fix }}$ & $0.007(1)$ & $-3(2)$ & $2.32(1)$ & 9 & 338 \\
\hline & & $\mathrm{Y}-\mathrm{O}_{2}$ & $2_{\text {fix }}$ & $0.004(8)$ & $-3(2)$ & $2.47(2)$ & & \\
\hline & $2^{\text {nd }}$ shell & Y-S & $1_{\text {fix }}$ & $0.008(5)$ & $-3(2)$ & $3.33(4)$ & & \\
\hline & & Y-Al & $2_{\text {fix }}$ & $0.012(5)$ & $-3(2)$ & $3.52(5)$ & & \\
\hline \multirow[t]{3}{*}{2} & $1^{\text {st }}$ shell & $\mathrm{Y}-\mathrm{O}$ & $10(1)$ & $0.012(2)$ & $-6(2)$ & $2.33(1)$ & 8 & 402 \\
\hline & $2^{\text {nd }}$ shell & Y-S & $1_{\text {fix }}$ & $0.009(5)$ & $-6(2)$ & $3.88(5)$ & & \\
\hline & & Y-Al & $1_{\text {fix }}$ & $0.006(3)$ & $-6(2)$ & $3.42(3)$ & & \\
\hline \multirow[t]{3}{*}{3} & $1^{\text {st }}$ shell & $\mathrm{Y}-\mathrm{O}$ & $10(1)$ & $0.013(1)$ & $-4(1)$ & $2.33(1)$ & 8 & 334 \\
\hline & $2^{\text {nd }}$ shell & Y-S & $1_{\text {fix }}$ & $0.008(3)$ & $-4(1)$ & $3.34(3)$ & & \\
\hline & & Y-Al & $2_{\mathrm{fix}}$ & $0.011(5)$ & $-4(1)$ & $3.92(4)$ & & \\
\hline
\end{tabular}
The EXAFS of the B-YSO4-ads standard was also fitted with the same three atomistic models presented in Fig. 4 but without sulfate included (Fig. S2) to analyze the sensitivity of the fit to the presence of sulfate. The Al-O distances obtained with these new fits (Table S3) were almost identical to those calculated when including sulfate shells (Table 2), with the exception in the monodentate inner sphere configuration, which was a bit longer. Thus, the presence of $\mathrm{Al}$ is consistent in the two models, with and without sulfate. However, the fits obtained with the sulfate group included showed lower values of the agreement factor (reduced chi-square) (compare Table 2 and Table S3). This discussion highlights the difficulties of the EXAFS technique to discern the 
presence of low-Z backscatterers, in particular in disordered systems such as the one present here.

These results are consistent with those presented by Rabung et al. where Gd and Lu were shown to adsorb onto $\gamma-\mathrm{Al}_{2} \mathrm{O}_{3}$ to form inner sphere complexes. ${ }^{47} \mathrm{Lu}$, which is considered a HREE such as $\mathrm{Y}$, was shown to form a monodentate surface complex with a first shell of 7 atoms and a Lu-O distance of $2.28 \AA$. The longer Y-O distance found here for $\mathrm{Y}$ is consistent with its larger $\mathrm{Y}$ ionic radius. However, these authors could not detect any Lu-Al bonds in their EXAFS data. Other sorption studies of Eu onto $\gamma-\mathrm{Al}_{2} \mathrm{O}_{3}$ showed the formation of both monodentate and bidentate binuclear complexes. ${ }^{20}$ In contrast to this study and to the results of Rabung et al. on Al oxides, EXAFS studies of lanthanides sorbed onto ferric oxides have shown a predominance of bidentate innersphere complexes. ${ }^{47} \mathrm{Lu}$ adsorbed onto ferrihydrite at $\mathrm{pH} \geq 5.5$ yielded an Lu-O coordination number of 7 at a distance of $2.30 \AA$, and a second coordination shell was identified with a Lu-Fe interatomic distance at $3.38 \AA$ A. These EXAFS results were complemented by time-resolved laser fluorescence spectroscopy (TRLF) measurements that showed five water molecules surrounding the metal cations, which was interpreted as a bidentate inner sphere complex. ${ }^{22}$ The similar distance to the second shell found by Dardenne et al. ${ }^{22}$ and by us in these two different systems can be explained by the smaller size of $\mathrm{Lu}$ in comparison to $\mathrm{Y}$, which is compensated for by the longer $\mathrm{Fe}-\mathrm{O}$ bond distance in comparison to the Al-O bond, making possible a bidentate mononuclear sphere at $3.4 \AA$ in Fe oxides and $\mathrm{Al}$ oxides. Another study by Estes et al. reported Eu K-edge EXAFS data of Eu(III) sorbed onto hematite. ${ }^{19}$ They observed a decrease in the coordination number of the $\mathrm{Eu}-\mathrm{O}$ bond from 8 to 5 upon adsorption accompanied by a smaller Eu-Fe bond distance at $3 \AA$. This result was interpreted via molecular simulations as being due to the formation of an inner sphere bidentate 
mononuclear surface complex. Such a decrease in the coordination number was not observed in this study; the $\mathrm{CN}$ of the $\mathrm{Y}-\mathrm{O}$ correlation was maintained at $\sim 8 \pm 1$ for both the aqueous and surface complexes.

\section{Identification of Y species in waste samples from AMD treatment}

412 The $\mathrm{k}^{3}$-weighted EXAFS of the column samples (upper part) and standards (lower part) and their Fourier transform (FT) envelope functions with corrected phase-shifts are shown in Fig. 3. Visual comparisons of the EXAFS spectra of the column samples reveal a strong similarity between them, suggesting similar local order of $\mathrm{Y}$ in all samples. In addition, the EXAFS spectra of the column samples are very similar to solid references (B-YSO4-ads, B-Y-ads, B-Y-cop and A-Y-ads). They have a shoulder at $\sim 6.5 \AA^{-1}$, indicating a higher frequency which is absent in the aqueous samples (see arrow in Fig. 3).

Based on the PCA analyses (see Chapter S3), the reconstructed spectra indicated that only two components were required to describe the samples (Fig. S4). The two most likely Y species identified by target transformation of the standard spectra, were the BYSO4-ads and B-Y-ads references (Fig. S5). However, since their EXAFS signals are very similar, LCF of the EXAFS spectra of the waste samples from column treatments was performed using B-YSO4-ads and YSO4-sol (Fig. 3A, upper part) to quantify the proportions of different $\mathrm{Y}$ species in the waste samples. The use of these two standards would correspond to $\mathrm{YSO}_{4}{ }^{+}$adsorbed forming inner- and outer-sphere complexes, respectively.

The LCF results show that more than $75 \%$ of $\mathrm{Y}$ adopts a local geometry similar to that of the B-YSO4-ads reference (with the exception of sample W-Alm-C3-8, for which the 
432 sphere complexes (Table 3)). The waste samples were selected from the depth where the

433

434

435

436

437

438

439

440

441

442

443

\begin{tabular}{ccccc}
\hline Standard & C1-4 & C1-5 & C3-8 & C3-9 \\
\hline B-YSO4ads & $0.719 \pm 0.036$ & $0.867 \pm 0.038$ & $0.495 \pm 0.059$ & $0.746 \pm 0.061$ \\
YSO4-solution & $0.281 \pm 0.069$ & $0.133 \pm 0.071$ & $0.505 \pm 0.084$ & $0.254 \pm 0.085$ \\
\hline R-factor & 0.14 & 0.14 & 0.29 & 0.30 \\
$\chi 2$ & 133 & 154 & 371 & 392 \\
\hline
\end{tabular}

Table 3. Percentages of $\mathrm{Y}$ species in the column samples obtained from LCF of the EXAFS spectra. R-factor and $\chi^{2}$ are defined in Chapter S3 of the SI.

major proportion of $\mathrm{Al}$ precipitated, assuming basaluminite precipitation. However, other minor mineral species may have also been precipitated, such as Feoxyhydroxisulfate, due to the presence of small amount of Fe in the solids. Specifically, samples from Almagrera column (W-Alm-C3-8 and W-Alm-C3-9) presented higher Fe concentration than samples from Monte Romero treatment. REE can be also scavenged by amorphous Fe hydroxides in AMD neutralization environments, ${ }^{48}$ so a minor or almost negligible fraction of $\mathrm{Y}$ could be retained by the small proportion of ferric oxides precipitated in the selected samples, explaining the lower proportion of B-YSO4ads.

EXAFS spectra. R-factor and $\chi{ }^{2}$ are defined in Chapter S3 of the SI. 
448 ion pair with a monodentate configuration, with an Y-S interatomic distance of $3.5 \AA$.

449 Results from thermodynamic sorption model describe REE sorption onto basaluminite 450 via sorption of aqueous $\mathrm{REESO}_{4}{ }^{+}$. The use of an atomistic model using this positively 451 charged ion yields the best results for the EXAFS fitting of Y sorbed on basaluminite. 452 However, the EXAFS technique cannot confirm the presence of $\mathrm{YSO}_{4}{ }^{+}$sorbed into 453 basaluminite by itself, due to the low sensitivity to discern between $\mathrm{Al}$ and $\mathrm{S}$ neighbors. 454 Rather than this, the EXAFS fitting, together with the PDF, can confirm the strong interaction and the formation of inner-sphere surface complexes of $\mathrm{Y}$ onto basaluminite precipitates, via ligand exchange with $\mathrm{AlO}_{6}$ units of its structure. EXAFS analyses of column waste samples show that most of the $\mathrm{Y}$ is retained as the same inner-sphere sorbed species, $\mathrm{YSO}_{4}{ }^{+}$, with a low proportion of $\mathrm{YSO} 4+$ in outer-sphere configuration.

The description of the local structure of yttrium sorbed onto the basaluminite surface provided here complements the atomic configuration studies of other trace metals, such as As and Se oxyanions. ${ }^{44}$ The chemical similarity between yttrium and other HREE (from $\mathrm{Tb}$ to $\mathrm{Lu}$ ) suggests that similar environments could be present for the other elements of the same group. This fact has important environmental consequences, as the HREE would be strongly sorbed, via covalent bonds, which could result in their longterm immobilization at least until the host phase is dissolved or re-precipitated. A key question emerges about the long-term stability of the complex, particularly with an increase in the solution $\mathrm{pH}$. The structural evolution of pure basaluminite with increasing $\mathrm{pH}$ showed its recrystallization onto boehmite, releasing sulfate into the solution. ${ }^{45}$ Previous studies on poorly crystalline Fe phases from AMD such as 470 schwertmannite have shown a release of adsorbed toxic elements during aging due to recrystallization processes. $^{49}$ The occurrence of such processes in REE-doped basaluminite could result in the remobilization of REEs and of other potentially 
473 adsorbed toxic elements. The extent to which these processes can occur in natural

474 waters requires further investigation.

475 Further studies on the potential uptake of LREEs by basaluminite are necessary to 476 confirm and/or compare different structural mechanisms to those of their HREE 477 counterpart, as an step to develop separation methods for REEs. These investigations 478 will help to enhance a selective recovery of REE from AMD wastes and thus to 479 generate an economic value of the waste generated during the neutralization of AMD480 affected waters.

Supporting information. The supporting information contains 1) five chapters with detailed description of synthesis of reference materials, analytical procedures and aqueous speciation calculations, synchrotron experiments and data analyses, molecular dynamics simulations and the Phyton code used to generate PDF from AIMD simulations; 2) three 3 tables describing samples used for EXAFS measurements and the modeling parameters from EXAFS fitting; and 3) four figures illustrating fitting of EXAFS spectra.

Acknowledgements

490

This work was funded by the European EIT 'Morerecovery' and the Spanish SCYRE (CGL2016-468 78783-C2-R)] projects. A.L. was also funded by a FPI grant (BES2014-069978) and the "Make Our Planet Great Again" short-stay program. A.F.-M. acknowledges a grant from Labex OSUG@2020 (investissements d'avenir, ANR10

494 LABX56) for financial support of this research. A.L. thanks J. Bellés, M. Cabañas and 
496 Materials and Molecular Modelling Hub for computational resources, which is partially 497 funded by EPSRC (EP/P020194/1). This research utilised Queen Mary's Apocrita HPC 498 facility, supported by QMUL Research-IT. The authors would like to thank the ESRF 499 for in-house beamtime allocation at ID31 and the SOLEIL review committee for 500 beamtime allocation at BM30B-FAME on the French quota, proposal n. 30-02-1124. 
501

502

503

504

505

506

507

508

509

510

511

512

513

514

515

516

517

518

519

520

521

522

\section{References}

(1) Binnemans, K.; Jones, P. T.; Blanpain, B.; Van Gerven, T.; Yang, Y.; Walton, A.; Buchert, M. Recycling of rare earths: A critical review. J. Clean. Prod. 2013, 51, 1-22. https://doi.org/10.1016/j.jclepro.2012.12.037

(2) Kumar, R.; Jiang, C.; Wang, J.; Cietek, D.; Roth, J.; Gell, M.; Jordan, E. H. (2018). Low Thermal Conductivity Yttrium Aluminum Garnet Thermal Barrier Coatings Made by the Solution Precursor Plasma Spray: Part II-Planar Pore Formation and CMAS Resistance. J. Therm. Spray Techn. 2018, 27(5), 794-808. https://doi.org/10.1007/s11666-018-0727-x

(3) Noack, C. W.; Dzombak, D. A.; Karamalidis, A. K. Rare Earth Element Distributions and Trends in Natural Waters with a Focus on Groundwater. Environ. Sci. Technol. 2014, 48 (8), 4317-4326. https://doi.org/10.1021/es4053895.

(4) Evangelou V. P.; Zhang, Y. L. A Review: Pyrite Oxidation Mechanisms and Acid Mine Drainage Prevention. Crit. Rev. Environ. Sci. Technol. 1995, 25 (2), 141-199. https://doi.org/10.1080/10643389509388477.

(5) Coulton, R.; Bullen, C.; and Hallet, C. The design optimisation of active mine water treatment plants. Land Contam.Reclamat. 2003, 11, 273-280.

(6) Ackman, T. Sludge disposal from acid mine drainage treatment. U.S. Bureau of Mines, Report of Invest. 8672, 1982. Pittsburg, PA. 38 pp.

(7) Viadero, R. C.; Wei, X.; Buzby, K. M. Characterization and Dewatering Evaluation of Acid Mine Drainage Sludge from Ammonia Neutralization. Environ. Eng. Sci. 2006, 23 (4), 734-743. https://doi.org/10.1089/ees.2006.23.734. 
523 (8) Hedin, R. S.; Watzlaf, G. R.; Nairn, R. W. Passive Treatment of Acid Mine

524 Drainage with Limestone. J. Environ. Qual. 1994, 23 (6), 1338-1345. 525 https://doi.org/10.2134/jeq1994.00472425002300060030x.

526 (9) Younger, P. L.; Banwart, S. A.; Hedin, R. S. Mine Water Hydrology, Pollution, 527 Remediation 2002. https://doi.org/10.1007/978-94-010-0610-1.

528 (10) Cravotta, C. A. Size and performance of anoxic limestone drains to neutralize 529 acidic mine drainage. J. Environ. Qual. 2003, 32, 1277- 1289.

530 (11) Watzlaf, G. R.; Schroeder, K. T.; Kleinmann, R. L. P.; Kairies, C. L.; Nairn, R. W. 531 The Passive Treatment of Coal Mine Drainage; laboratory report DOE/NETL532 2004/1202; U.S. Department of Energy, National Energy Technology Laboratory: 533 Pittsburgh, PA, 2004.

534 (12) Ayora, C.; Macías, F.; Torres, E.; Lozano, A.; Carrero, S.; Nieto, J.-M.; Pérez535 López, R.; Fernández-Martínez, A.; Castillo-Michel, H. Recovery of Rare Earth 536 Elements and Yttrium from Passive-Remediation Systems of Acid Mine Drainage. 537 Environ. Sci. $\quad$ Technol. $2016, \quad 50 \quad$ (15) 8255-8262. 538 https://doi.org/10.1021/acs.est.6b02084.

539 (13) Ayora, C.; Caraballo, M. A.; Macias, F.; Rötting, T. S.; Carrera, J.; Nieto, J. M. 540 Acid Mine Drainage in the Iberian Pyrite Belt: 2. Lessons Learned from Recent Passive 541 Remediation Experiences. Environ. Sci. Pollut. Res. 2013, 20 (11), 7837-7853. 542 https://doi.org/10.1007/s11356-013-1479-2

543 (14) Bigham, J. M.; Nordstrom, D K. Iron and aluminum hydroxysulfate minerals from 544 acid sulfate waters. 2000 In: Jambor, J.L., Alpers, C.N., Nordstrom, D.K. (Eds.), Sulfate 545 Minerals, Crystallography, Geochemistry and Environmental Significance, vol. 40. 
546

547

548

549

550

551

552

553

554

555

556

557

558

559

560

561

562

563

564

565

566

567

Mineralogical Society of America Reviews in Mineralogy and Geochemistry, pp. 351403.

(15) Carrero, S.; Fernandez-Martinez, A.; Pérez-López, R.; Lee, D.; Aquilanti, G.; Poulain, A.; Lozano, A.; Nieto, J.-M. The Nanocrystalline Structure of Basaluminite, an Aluminum Hydroxide Sulfate from Acid Mine Drainage. Am. Mineral. 2017, 102 (12), 2381-2389. https://doi.org/10.2138/am-2017-6059.

(16) Gammons, C. H.; Wood, S. A.; Pedrozo, F.; Varekamp, J. C.; Nelson, B. J.; Shope, C. L.; Baffico, G. Hydrogeochemistry and Rare Earth Element Behavior in a Volcanically Acidified Watershed in Patagonia, Argentina. Chem. Geol. 2005, 222 (34), 249-267. https://doi.org/10.1016/i.chemgeo.2005.06.002.

(17) Lozano, A.; Ayora, C.; Fernández-Martínez, A. Sorption of rare earth elements onto basaluminite: the role of sulfate and pH. Geochim. Cosmochim. Acta 2019. 258, $50-62$.

(18) Gimeno Serrano, M. J.; Auqué Sanz, L. F.; Nordstrom, D. K. REE Speciation in Low-Temperature Acidic Waters and the Competitive Effects of Aluminum. Chem. Geol. 2000, 165, 167-180. https://doi.org/10.1016/S0009-2541(99)00166-7(19) Estes, S. L.; Arai, Y.; Becker, U.; Fernando, S.; Yuan, K.; Ewing, R. C.; Zhang, J.; Shibata, T.; Powell, B. A. A Self-Consistent Model Describing the Thermodynamics of Eu(III) Adsorption onto Hematite. Geochim. Cosmochim. Acta 2013, 122, 430-447. https://doi.org/10.1016/j.gca.2013.08.023.

(20) Yang, S.; Sheng, G.; Montavon, G.; Guo, Z.; Tan, X.; Grambow, B; Wang, X. Investigation of $\mathrm{Eu}(\mathrm{III})$ immobilization on $\gamma-\mathrm{Al}_{2} \mathrm{O}_{3}$ surfaces by combining batch 
568 technique and EXAFS analyses: Role of contact time and humic acid. Geochim. 569 Cosmochim. Acta 2013, 121, 84-104.

570 (21) Fan, Q. H.; Tan, X. L.; Li, J. X.; Wang, X. K.; Wu, W. S.; Montavon, G. Sorption 571 of Eu(III) on Attapulgite Studied by Batch, XPS, and EXAFS Techniques. Environ. Sci. 572 Technol. 2009, 43 (15), 5776-5782. https://doi.org/10.1021/es901241f..

573 (22) Dardenne, B. K.; Schäfer, T.; Denecke, M. A.; Rothe, J.; Kim, J. I. Identification 574 and Characterization of Sorbed Lutetium Species on 2-Line Ferrihydrite by Sorption 575 Data Modeling, TRLFS and EXAFS. Radiochim. Acta 2001, 89, 469-479.

576 (23) Allen, P. G.; Bucher, J. J.; Shuh, D. K.; Edelstein, N. M.; Craig, I. Coordination 577 Chemistry of Trivalent Lanthanide and Actinide Ions in Dilute and Concentrated 578 Chloride Solutions FT Magnitude. Inorg. Chem. 2000, 39 (11), 595-601.

579 (24) Lindqvist-Reis, P.; Lambe, K.; Pattanaik, S.; Persson, I.; Sandström, M. Hydration 580 of the Yttrium (III) Ion in Aqueous Solution . An X-Ray Diffraction and XAFS 581 Structural Study. J. Phys. Chem. B 2000, 104, 402-408. 582 https://doi.org/10.1021/jp992101t.

583 (25) Yaita, T.; Narita, H.; Suzuki, S.; Tachimori, S.; Motohashi, H.; Shiwaku, H. 584 Structural Study of Lanthanides(III) in Aqueous Nitrate and Chloride Solutions by 585 EXAFS. J. Radioanal. Nucl. Chem. 1999, 239 (2), 371-375. 586 https://doi.org/10.1007/BF02349514.

587 (26) Duvail, M.; Ruas, A.; Venault, L.; Moisy, P.; Guilbaud, P. Molecular Dynamics 588 Studies of Concentrated Binary Aqueous Solutions of Lanthanide Salts: Structures and 589 Exchange Dynamics. Inorg. Chem. 2010, 49 (2), 519-530. https://doi.org/10.1021/ic9017085. 
591

592

593

594

595

596

597

598

599

600

601

602

603

604

605

606

607

608

609

610

611

612

613

(27) Kowall, T.; Foglia, F.; Helm, L.; Merbach, A. E. Molecular Dynamics Simulation Study of Lanthanide Ions $\mathrm{Ln}^{3+}$ in Aqueous Solution Including Water Polarization.

Change in Coordination Number from 9 to 8 along the Series. J. Am. Chem. Soc. 1995, 117 (13), 3790-3799. https://doi.org/10.1021/ja00118a015.

(28) Ohta, A.; Kagi, H.; Tsuno, H.; Nomura, M.; Kawabe, I. Influence of Multi-Electron Excitation on EXAFS Spectroscopy of Trivalent Rare-Earth Ions and Elucidation of Change in Hydration Number through the Series. Am. Mineral. 2008, 93 (8-9), 13841392. https://doi.org/10.2138/am.2008.2628.

(29) Rizkalla, E. N., Choppin, G. R. Lanthanides and Actinides Hydration and Hydrolysis. In: Handbook on the Physics and Chemistry of Rare Earths. 1994. (Gschneider, K. A., Eyring, L., Choppin, G. R., Lander, G. H., eds.) Vol. 18 Lanthanides/Actinides: Chemistry. Elsevier Science B.V., Amsterdam, The Netherlands.

(30) Duvail, M.; Spezia, R.; Vitorge, P. A Dynamic Model to Explain Hydration Behaviour along the Lanthanide Series. Chemphyschem 2008, 9, 693-696. https://doi.org/10.1002/cphc.200700803.

(31) Janicki, R.; Starynowicz, P.; Mondry, A. Lanthanide carbonates. Eur. J. Inorg. Chem. 2011, 24, 3601-3616. https://doi.org/10.1002/ejic.201100184.

(32) Jeanvoine, Y.; Miró, P.; Martelli, F.; Cramer, C. J.; Spezia, R. Electronic structure and bonding of lanthanoid(III) carbonates. Phys. Chem. Chem. Phys. 2012, 14 (43), 14822-14831. https://doi.org/10.1039/c2cp41996c.

(33) Harris, S. M.; Nguyen, J. T.; Pailloux, S. L.; Mansergh, J. P.; Dresel, M. J.; Swanholm, T. B.; Gao, T.; Pierre, V. C. Gadolinium complex for the catch and release 
614 of phosphate from water. Environ. Sci. Technol. 2017, 51 (8), 4549-4558. 615 https://doi.org/10.1021/acs.est.6b05815.

616 (34) Luo, Y. R.; Byrne, R. H. Carbonate complexation of yttrium and the rare earth 617 elements in natural rivers. Geochim. Cosmochim. Acta 2004, 68, 691-699.

618

619

620

621

622

623

624

625

626

627

628

629

630

631

632

633

634

635

(35) Torres, E.; Auleda, M. A Sequential Extraction Procedure for Sediments Affected by Acid Mine Drainage. J. Geochemical Explor. 2013, 128, 35-41.

(36) Parkhurst, D. L.; Appelo, C. A. J. User's guide to PhreeqC (version 2.18) A computer program for speciation, and inverse geochemical calculations, U.S. Department of the Interior, U.S. Geological Survey 1999.

(37) Blanc, P.; Lassin, A.; Piantone, P.; Azaroual, M.; Jacquemet, N.; Fabbri, A.; Gaucher, E. C. Thermoddem: A Geochemical Database Focused on Low Temperature Water/Rock Interactions and Waste Materials. Appl. Geochemistry 2012, 27 (10), 21072116. https://doi.org/10.1016/j.apgeochem.2012.06.002.

(38) Juhás, P.; Davis, T.; Farrow, C. L.; Billinge, S. J. L. PDFgetX3: a rapid and highly automatable program for processing powder diffraction data into total scattering pair distribution functions. J. Appl. Crystallogr. 2013, 46, 560-566. https://doi.org/10.1107/S0021889813005190.

(39) Proux, O.; Biquard, X.; Lahera, E.; Menthonnex, J. J.; Prat, A.; Ulrich, O.; Soldo, Y.; Trévisson, P.; Kapoujyan, G.; Perroux, G.; Taunier, P.; Grand, D.; Jeantet, P.; Deleglise, M; Roux, J-P. and Hazemann, J-L. FAME A New Beamline for XRay Absorption Investigations of Very Diluted Systems of Environmental, Material and $\begin{array}{llll}\text { Biological Interests. } & \text { Phys. } & \text { Scr. } & \text { 2005, }\end{array}$ https://doi.org/10.1238/physica.topical.115a00970. 
637

638

639

640

641

642

643

644

645

646

647

648

649

650

651

652

653

654

655

656

657

658

659

(40) Hutter, Y.; Iannuzzi, M.; Schiffmann, F.; VandeVondele, J. CP2K: Atomistic Simulations of Condensed Matter Systems. Wiley Interdiscip. Rev. Comput. Mol. Sci. 2014, 4, 15-25.

(41) Zhang, Y.; Yang, W. Comment on 'Generalized Gradient Approximation Made Simple”. Phys. Rev. Lett. 1998, 80, 890-890.

(42) Grimme, S.; Antony, J.; Ehrlich, S.; Krieg, H. A Consistent and Accurate Ab Initio Parametrization of Density Functional Dispersion Correction (DFT-D) for the 94 Elements H-Pu. J. Chem. Phys. 2010, $132 \quad$ (15), 154104. https://doi.org/10.1063/1.3382344.

(43) Juhás, P.; Farrow, C. L.; Yang, X.; Knox, K. R.; Billinge, S. J. L. Complex Modeling: A Strategy and Software Program for Combining Multiple Information Sources to Solve Ill Posed Structure and Nanostructure Inverse Problems. Acta Crystallogr. Sect. A Found. Adv. 2015, A71, 562-568. https://doi.org/10.1107/S2053273315014473.

(44) Carrero, S.; Fernandez-Martinez, A.; Pérez-López, R.; Poulain, A.; Salas-Colera, E.; Nieto, J. M. Arsenate and Selenate Scavenging by Basaluminite: Insights into the Reactivity of Aluminum Phases in Acid Mine Drainage. Environ. Sci. Technol. 2017, 51 (1), 28-37. https://doi.org/10.1021/acs.est.6b03315.

(45) Lozano, A.; Fernández-Martínez, A.; Ayora, C.; Poulain, A. Local Structure and Ageing of Basaluminite at Different $\mathrm{pH}$ Values and Sulphate Concentrations. Chem. Geol. 2018, 496, 25-33. https://doi.org/10.1016/j.chemgeo.2018.08.002.

(46) Cruz-Hernández, P.; Carrero, S.; Pérez-López, R.; Fernández-Martínez, A.; Lindsay, M. B .J.; Dejoie, C.; Nieto, J. M. Influence of As(V) on precipitation and 
660 transformation of schwertmannite in acid mine drainage-impacted waters. Eur. J. 661 Mineral. 2018 https://doi.org/10.1127/ejm/2019/0031-2821.

662 (47) Rabung, Th.; Geckeis, H.; Wang, X. K.; Rothe, J.; Denecke, M. A.; Klenze, R.; 663 Fanghäel, Th. $\mathrm{Cm}(\mathrm{III})$ sorption onto $\gamma-\mathrm{Al}_{2} \mathrm{O}_{3}$ : New insight into sorption mechanisms by 664 time-resolved laser fluorescence spectroscopy and extended X-ray absorption fine 665 structure. Radiochim. Acta 2006, 94, 609-618.

666 (48) Verplanck, P. L.; Nordstrom, D. K.; Taylor, H. E.; Kimball, B. A. Rare earth 667 element partitioning between hydrous ferric oxides and acid mine water during iron 668 oxidation. Appl. Geochem. 2004, 19, 1339-1354.

669 (49) Acero, P.; Ayora, C.; Torrentó, C.; Nieto, J. M. The Behavior of Trace Elements 670 during Schwertmannite Precipitation and Subsequent Transformation into Goethite and 671 Jarosite. Geochim. Cosmochim. Acta 2006, 70 (16), 4130-4139. 